\title{
Cross-talk between the inflammatory response, sympathetic activation and pulmonary infection in the ischemic stroke
}

\author{
Pawel J Winklewski ${ }^{*}$, Marek Radkowski ${ }^{2}$ and Urszula Demkow ${ }^{3}$
}

\begin{abstract}
The immune system response and inflammation play a key role in brain injury during and after a stroke. The acute immune response is responsible for secondary brain tissue damage immediately after the stroke, followed by immunosuppression due to sympathetic nervous system activation. The latter increases risk of infection complications, such as pneumonia. The pneumonia-related inflammatory state can release a bystander autoimmune response against central nervous system antigens, thereby initiating a vicious circle. The aim of this review is to summarize the relationship between ischemic stroke, sympathetic nervous system activation and pulmonary infection.
\end{abstract}

Keywords: Stroke, Brain injury, Immune response, Sympathetic nervous system, Lung injury, Pneumonia

\section{Introduction}

It is estimated that pulmonary and urinary tract infections occur in up to one third of patients suffering from ischemic stroke within the first days after the vascular event [1,2]; however, frequency of these infections varies between studies [3]. The largest trial undertaken to investigate the effect of pneumonia on mortality in hospitalized patients with acute stroke reported a $27 \%$ 30-day mortality rate in 635 patients due to pneumonia compared to $4 \%$ death rate among patients free from severe respiratory infections $(P<0.001)$ [4]. The most important predictors of post-stroke infection include older age, stroke severity (that is National Institutes of Health Stroke Scale of more than 16 in 0 to 42 scale, Barthel Index of less than 5 in 0 to 20 scale, Glasgow Coma Scale score of less than 9), larger area of the infarct, and dysphagia $[4,5]$.

Dysphagia is a well-recognized risk factor for post-stroke pneumonia. Traditionally, it has been explained by abnormal dopamine transmission and/or a decrease of substance $\mathrm{P}$ in the gastrointestinal tract resulting in the impairment of the swallowing reflex [6]. Dysphagia is a frequent indication for tube feeding as a prophylactic

\footnotetext{
* Correspondence: pawelwinklewski@wp.pl

${ }^{1}$ Institute of Human Physiology, Medical University of Gdansk, Tuwima Street 15, 80-210 Gdansk, Poland

Full list of author information is available at the end of the article
}

procedure against post-stroke pneumonia, however, with very limited effects [7]. As none of the modalities used to treat dysphagia provide efficient protection against post-stroke pneumonia, it is warranted to discern alternative etiologies for the respiratory insult, including a stroke-induced systemic immune response [3]. This assumption corresponds with the observation that up to half of the patients presenting with pneumonia do not aspirate [8]. Furthermore, Prass et al. [9] demonstrated that experimental stroke can promote bacterial aspiration from harmless intranasal colonization, leading to pneumonia. Prevention of infections by $\beta$-adrenergic receptors ( $\beta$-ARs) blockade suggests that immunodepression due to sympathetic nervous system (SNS) hyperactivity is essential for the development of aspiration-induced pneumonia [10]. The insular cortex strokes associated with excessive sympathetic stimulation increase the risk of post-stroke pneumonia in humans [11].

Acute immune activation after the stroke is responsible for secondary brain injury [12,13]. It is followed by immunosuppression, consequently increasing the risk of infections such as pneumonia. Recently, multiple experimental and clinical studies were performed to explain the relationship between infection after the stroke and immunosuppression induced by the SNS $[9,10,14]$.

Ischemic stroke gives rise to an intense activation of the SNS and the release of catecholamines [9,10]. Primary 
(bone marrow and thymus) and secondary (spleen and lymph nodes) lymphoid organs are abundantly innervated by autonomic, mostly sympathetic efferent fibers. The SNS primary neurotransmitter - norepinephrine is released into the lymphoid tissue and modulates the function of immune cells [15]. The stroke-induced SNS activation is responsible for lymphopenia, impaired function of monocytes, shift from Th1 to Th2 cytokine production and increased lymphocyte apoptosis, observed in the affected patients [9-11]. Pharmacological inhibition of the peripheral SNS activation with a beta-blocker was shown to prevent immunosuppression in experimental stroke [10]. A retrospective analysis showed that the use of beta-blockers is associated with reduced risk of early death in patients with ischemic stroke [16]. The aim of this review is to discuss the relationship between ischemic stroke, SNS activation and pulmonary infection.

\section{Immune system in stroke}

Ischemic cerebral stroke results from a transient or permanent reduction in local blood flow. Focal cerebral ischemia initiates a complex process including the release of neurotransmitters and activation of the immune system. Recently, the inflammatory mechanisms involved in the pathogenesis of brain injury and brain repair mechanisms (that is neural plasticity) have received considerable attention [12,13].

The response of the immune system to stroke is biphasic, with early transient activation lasting up to 24 hours $[17,18]$ followed by systemic immunodepression, called brain-induced immunosuppression $[14,18]$. The suppression of cell-mediated immunity (lymphopenia, monocyte deactivation, shift from Th1 to Th2 cytokine production) 72 hours after experimental stroke is often associated with spontaneous bacteremia and pneumonia [10]. Prass et al. [10] demonstrated that reduced IFN- $\gamma$ production as well as impaired natural killer (NK) and T cell response are the critical stroke-related failures in antibacterial defense. Other animal studies demonstrated decrease in IL-10 release by endotoxinstimulated whole blood cells after infusion of IL-1 $\beta$ into the brain. This effect was attributed to activation of the hypothalamic-pituitary-adrenal (HPA) axis and the sympatho-adrenal medullary axis [19].

\section{Spleen}

Offner et al. [17] observed that 6 and 22 hours after experimental stroke in mice, activated spleen cells secreted significantly higher amounts of TNF- $\alpha$, IFN- $\gamma$, IL-6, monocyte chemotactic protein 1 (MCP-1), and IL-2 than splenocytes in control mice. Moreover, stimulated splenocytes from stroke-injured animals strongly expressed chemokines and chemokine receptors $(\mathrm{CCR})$, including macrophage inflammatory protein 2 (MIP-2) and CCR2,
CCR7 and CCR8 6 hours after stimulation; MIP-2, IFN$\gamma$-induced protein 10 (IP-10), CCR1, and CCR2 were expressed 22 hours after stimulation. Experimental stroke increased the release of inflammatory cytokines from activated T cells [17]. Twenty-four hours later, a higher CD4/CD8 $\mathrm{T}$ cell ratio and enhanced production of TNF- $\alpha$ and IFN- $\gamma$ by blood and spleen lymphocytes were reported [18].

These observations correspond with the finding of Hardy et al. that phenylephrine (an $\alpha_{1-}$ AR agonist) induces contractions of the spleen in a dose-dependent manner [20]. Therefore, the spleen may serve as a dynamic reservoir of leukocytes, which are mobilized by catecholamines and migrate to the injured brain. Interestingly, the reduction in spleen size could be inhibited by $\alpha_{1}$-AR antagonist prazosin. However, this effect did not influence the infarct size, demonstrating that these two events are not directly linked to each other [21]. Offner et al. [22] suggested that spleen shrinkage was due to profound apoptosis of the lymphocyte population. However, it seems unlikely that even an extensive apoptosis would eliminate lymphocytes massively to reduce the spleen size by $40 \%$, yet preserve their relative count in the organ [22]. Moreover, according to another report, the spleen may release large numbers of platelets upon low-dose epinephrine infusion [23]. The platelets may, as described below, significantly contribute to the development of an acute inflammatory response in the brain.

\section{Liver}

Wong et al. [24] reported that noradrenergic innervation of the liver modulates the function of intrahepatic invariant $\mathrm{NK} T$ cells accounting for systemic immune suppression after experimental ischemic stroke. Invariant NK T cells are a unique subset of lymphocytes that express a repertoire of highly restricted $\mathrm{T}$ cell receptors. These receptors recognize microbe-specific or endogenous glycolipids presented by the major histocompatibility complex class I-like molecule CD1d. They are believed to play a critical role in host defense to various microbial pathogens as they are capable for a rapid release of cytokines (such as INF- $\gamma$ ) and chemokines. These mediators contribute considerably to the recruitment and activation of various leukocyte subsets, including neutrophils and macrophages. Invariant NK T cells reside in the vasculature, mainly in the liver and spleen [25]. Either blockade of $\beta$-ARs with propranolol or depletion of noradrenergic nerve terminals in the liver boost the immune response by increasing IFN- $\gamma$ secretion from invariant NK T cells. Conversely, injection of noradrenaline into the liver downregulates inflammatory mechanisms by attenuating the functions of invariant NK T cells [24]. 


\section{Cerebral vessels}

Cerebral ischemia induces the expression of TNF- $\alpha$, IL-1 $\beta$, IL-6, inducible nitric oxide synthase (iNOS) and TNF- $\alpha$ receptors in the endothelium of cerebral arteries $[26,27]$. Furthermore, TNF- $\alpha$, IL-1 $\beta$, epidermal growth factor (EGF), and basic fibroblast growth factor (bFGF) can modify the expression and function of endothelin receptors in cultured rat middle cerebral arteries [28]. Upregulation of the endothelin receptor in experimental stroke may be due to the effect of cytokines and growth factors [27]. This mechanism may facilitate cerebral vessel contraction in vivo, and consequently worsen cerebrovascular risk by lowering cerebrovascular reserves and increase the vulnerability of the brain to cerebral ischemia [29].

Despite intensive studies, the physiological role of the SNS in the regulation of cerebral blood flow remains far from clear [30-32]. Studies demonstrating SNS involvement in the regulation of cerebral blood flow [33,34], indicate that the stroke-induced SNS activity fluctuations are a significant factor of impaired cerebral autoregulation [35,36]. In particular, massive release of catecholamines may further amplify the effects of upregulated endothelin receptor. Thus, the pro-inflammatory signals and SNS activation promote microvascular occlusion and may increase the infarct size [37]. Regulation of cerebral blood flow might also be impaired by the administration of tissue plasminogen activator used to improve the perfusion of ischemic areas [38].

Early restoration of blood flow remains the treatment of choice for limiting brain injury following ischemic stroke. While reperfusion of the ischemic brain is desirable, tissue damage may result from reperfusion per se. The accumulation of $\mathrm{T}$ cells in post-capillary venules is accompanied by the recruitment of adherent platelets [39]. As mentioned above, large numbers of platelets are released from the spleen following sympathetic stimulation [23]. A novel concept of 'thrombo-inflammation' suggests that there is a strong correlation between thrombus formation and inflammation, and early platelet adhesion/ activation may exacerbate infarct development following cerebral ischemia and reperfusion $[40,41]$.

\section{Blood-brain barrier breakdown}

A schematic time-course of the microglial cells, neutrophils and T lymphocytes after stroke was shown in Figure 1.

Microglial cells, the resident macrophages of the brain, are activated within minutes of the onset of ischemia. They produce a plethora of pro-inflammatory mediators, including reactive oxygen species (ROS), IL-1 $\beta$, IL- 6 , and TNF- $\alpha[42,43]$, which further exacerbate tissue damage [44]. Microglial cell activation plays a crucial role in the increase of blood-brain barrier permeability and the early infiltration of circulating leukocytes into the brain $[45,46]$.
The post-ischemic peak of microglial proliferation is observed at 48 to 72 hours after focal cerebral ischemia and may last for several weeks after the initial injury $[47,48]$.

In contrast to rapid response of resident microglia, blood-derived leukocytes are recruited to the brain tissue usually with a delay of hours to a few days. Neutrophils are among the first leukocytes to infiltrate the ischemic brain (30 minutes to a few hours of focal cerebral ischemia), peak (24 to 72 hours), and then decrease rapidly $[49,50]$. On the other hand, Gelderblom et al. [51] questioned this scenario, suggesting that the infiltration of other inflammatory cells, including macrophages, lymphocytes, and dendritic cells may precede neutrophil influx. Activation of spleen neutrophils under physiological conditions is modulated by the SNS [52]. Spleen contraction induced by the SNS activation and blood-brain barrier breakdown after ischemic stroke may facilitate their migration to the injured brain. Nevertheless, the clear role of neutrophils in the pathogenesis of ischemic stroke is far from being elucidated.

$\mathrm{T}$ lymphocytes are central to the development of a sustained inflammatory response and accumulate in the ischemic brain within a few hours of reperfusion [53,54]. $\mathrm{T}$ cells may contribute to brain injury through several potential mechanisms. Cytokines and chemokines released by $\mathrm{T}$ helper $\left(\mathrm{T}_{\mathrm{H}}\right)$ and $\mathrm{T}$ cytotoxic $\left(\mathrm{T}_{\mathrm{C}}\right)$ cells (which are IL-12, IL-17, and IL-23) may exacerbate post-stroke inflammation and increase infarct area $[55,56]$. Furthermore, cytokines and chemokines are likely to increase the expression of vascular adhesion molecules and attract other immune cells into the brain resulting in widespread apoptosis [57]. CD3+ cells are a major source of INF- $\gamma$ and perforin in the ischemic hemisphere [58] whereas $\mathrm{T}_{\mathrm{C}}$ cells directly induce cell necrosis and apoptosis by the release of cytotoxins or activation of the Fas receptor [59]. Finally, T lymphocytes may release large amounts of ROS [53]. Thus, it is commonly accepted that $\mathrm{T}$ cells are a major source of pro-inflammatory cytokines in the brain after the stroke [60].

In patients with the ischemic event, the number of $\mathrm{T}, \mathrm{B}$ and NK lymphocytes in the circulation is quickly reduced $[10,61]$, possibly as an endogenous protective mechanism attenuating local inflammatory process in the brain [61]. A profound systemic immunodepression occurs as soon as 12 hours after the stroke and persists for several weeks $[10,62]$. This immunodepression is due to SNS and HPA axis hyperactivity [10] and is mediated by $\beta 2$ adrenergic receptors [63]. According to a recent emerging concept, the immunodepression after stroke is attributable to the increase in the number of systemic $\mathrm{CD} 4^{+} \mathrm{CD} 25^{+} \mathrm{FoxP}^{+}$ regulatory $\mathrm{T}$ (Treg) cells $[18,22]$. Increased percentage of Treg cells in bone marrow and their mobilization to the circulation is facilitated by the stroke-induced activation of the SNS via $\beta 2$ - and $\beta 3$-ARs signaling, respectively [64]. 


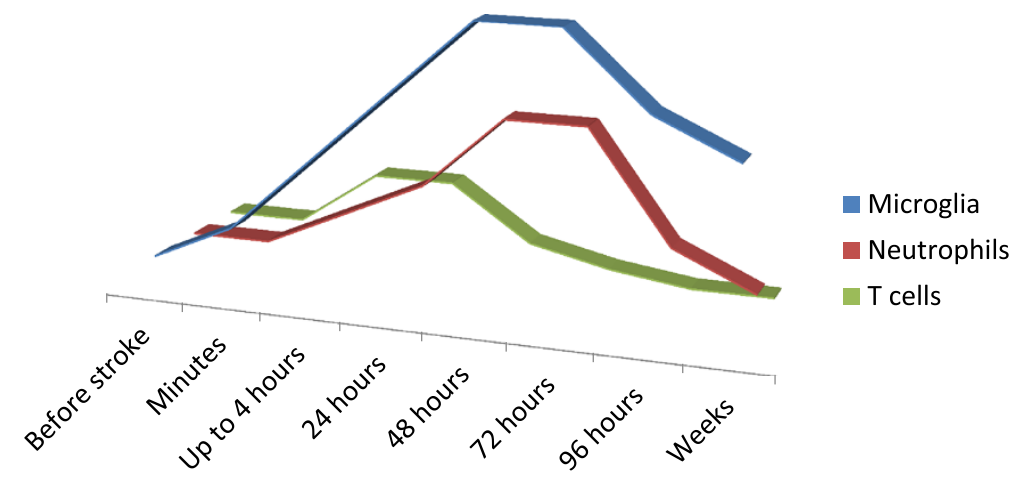

Figure 1 A schematic time-course of the microglial cells, neutrophils and T lymphocytes after ischemic stroke. Percent increase in cell count after experimental stroke in ischemic hemisphere has been estimated from the scientific literature by the authors [10,47-50,61].

Systemic immunodepression is not unique to ischemic stroke, and can also follow another brain injury including traumatic events or brain surgery [14]. Treg-mediated immunosuppression and increased susceptibility to subsequent bacterial infections can be attributed to the deficit of IFN- $\gamma$ resulting in insufficient activation of phagocytic cells at the site of infection [64].

\section{Brain-lung cross-talk}

Neurologic conditions that cause abrupt, rapid and extreme elevation in intracranial pressure give rise to an intense activation of the SNS and the release of catecholamines [65]. The non-neurological consequences of brain injury show similarities regardless of the brain insult and, in particular, include neurogenic pulmonary edema (NPE) [66].

\section{Acute lung injury (ALI) as a consequence of acute brain injury}

ALI is a diffuse heterogeneous lung injury characterized by hypoxemia, non-cardiogenic pulmonary edema, low lung compliance and widespread capillary leakage [67]. It has been demonstrated that approximately one third of patients with acute brain injury develop ALI. Patients with concomitant ALI seem to have a worse prognosis $[68,69]$. The pathogenesis of ALI includes NPE, the activation of neutrophils, inflammatory mediator release, alveolar/capillary barrier damage, activation of the coagulation system, surfactant depletion and infections [64]. Brain injury might also increase lung vulnerability to subsequent deleterious mechanical or ischemia-reperfusion injury, thereby increasing the risk of subsequent respiratory failure [70].

NPE is a well-recognized complication of central nervous system (CNS) injury [66]. The proposed mechanisms governing NPE include a massive sympathetic discharge following severe brain injury causing alveolar/capillary barrier damage, intra-alveolar accumulation of proteinrich edema fluid, hemorrhage, and atelectasis. The precise origin of sympathetic outflow has not yet been identified. Nevertheless, it is believed that the 'NPE trigger zones' include the hypothalamus and the medulla, specifically areas A1 and A5, the nuclei of the solitary tract, and the area postrema [71]. It has been hypothesized that a massive SNS discharge following CNS injury directly affects the pulmonary vascular bed via $\alpha$ - and $\beta$-ARs, leading to isolated pulmonary venoconstriction and/or endothelial damage. This theory, termed 'pulmonary venule adrenergic hypersensitivity', can explain the direct impact of nervous system on the pulmonary endothelium, not intermediated by hemodynamic changes [66]. Nevertheless, the most established is the 'blast theory', which combines hemodynamic and high permeability mechanisms [72]. According to Rassler et al. the severity of pulmonary edema evoked by experimental intravenous injection of catecholamines correlates with pulmonary venous hypertension [73]. Moreover, Theodore and Robin (1975) proved that an increase in the pulmonary capillary wedge pressure augmented fluid filtration into the pulmonary interstitium [72].

There is mounting evidence that a systemic inflammatory response may also play a pivotal role in the development of pulmonary dysfunction after traumatic brain injury [74,75] or subarachnoid hemorrhage [76]. It seems that the initial sympathetic stimulation originating from the SNS may trigger a cascade of events in the lungs, including endothelial cell dysfunction and a systemic inflammatory response with pulmonary infiltration of neutrophils and cytokine release [75]. Cerebral hemorrhage increases the expression of intracellular adhesion molecules in both brain and lungs, resulting in progressive neutrophil recruitment to the lung interstitium and alveolar spaces with the disruption of alveolar structures [77]. It has been proposed that sympathetic activation of the lungs may provoke local release of cytokines and chemokines [76]. Furthermore, in experimental settings, catecholamines seem to activate $\mathrm{NF} \kappa \mathrm{B}$ in macrophages with subsequent inflammatory cytokine production 
(IL-6, TNF- $\alpha$ and IL-1 $\beta$ ) in the lungs in a dose-dependent manner. Upregulation of the phagocyte response via $\alpha 2$-ARs enhances the acute inflammatory response [78].

In rats, NPE induced by lethal injury of the brain is characterized by increase of pro-inflammatory cytokines, in particular IL-6, and accumulation of immune cells in bronchoalveolar lavage fluid $[79,80]$. The histological assessment of lung tissue in this model reveals infiltration of inflammatory cells like neutrophils within interstitial spaces [80]. Experimental studies showed that norepinephrine infusion enhances expression of pro-inflammatory cytokines such as IL-6, IL- $1 \alpha$ and IL- $1 \beta$ in lung tissue and in bronchoalveolar lavage fluid [73]. The systemic increase in catecholamines augments the release of IL- 6 from lung macrophages via $\beta_{2}$-ARs, which in turn contributes to the development of a hypercoagulable state [81]. Avlonitis et al. [79] demonstrated that administration of $\alpha$-adrenergic antagonists prevented the development of inflammatory lung injury by reducing systemic inflammation and preserving capillary-alveolar membrane integrity. Thus, the experimental data strongly supports the hypothesis that the systemic increase of catecholamines due to the SNS activation contributes to local inflammation in lungs and impairs capillary-alveolar membrane integrity via $\alpha$ - and $\beta$-ARs located on phagocytes and in the pulmonary vascular bed.

\section{Stroke and lung injury}

Mascia proposed a 'double hit model' to explain the pathogenesis of lung failure associated with acute brain injury [75]. The model was originally developed for traumatic brain injury; however, it shares several typical features with stroke-induced respiratory distress syndrome. Although, stroke pathophysiology significantly differs from traumatic injury brain insult it is a starting point for the local inflammation. It was shown that severe ischemic stroke was associated with an increase in the total lung water content, which might have been of neurogenic origin [82]. Nevertheless, even if the fully developed NPE does not emerge after ischemic stroke, an increase in the permeability of the alveolar/capillary barrier and local inflammatory state may favor subsequent infections.

Modulation of bulbar reflexes, drowsiness, bed rest and decreased ventilation rate combined with deep immunosuppression after stroke may trigger the development of pneumonia. Clinical data indicate that Streptococcus pneumoniae, the most common cause of bacterial community-acquired pneumonia [83] is also a predominant agent responsible for respiratory infections, prolonged hospitalization, and lethality in stroke patients [3]. By employing animal studies it was shown that nasal inoculation of as little as 200 colony-forming units of Streptococcus pneumonia causes severe pneumonia and bacteremia after experimental stroke, whereas at least 200,000 colony-forming units are needed to induce pneumonia in controls [9]. Other common pathogens such as Chlamydophila pneumoniae and Haemophilus influenzae also contribute to the development of severe infectious complications [83].

\section{Post-stroke autoimmune responses}

The teleological explanation for post-stroke immunosuppression is that it prevents the CNS from developing adaptive immune responses directed against self-components. After stroke, due to brain-blood barrier breakdown, lymphocytes infiltrate the ischemic brain allowing for contact with CNS antigens from various CNS cell types

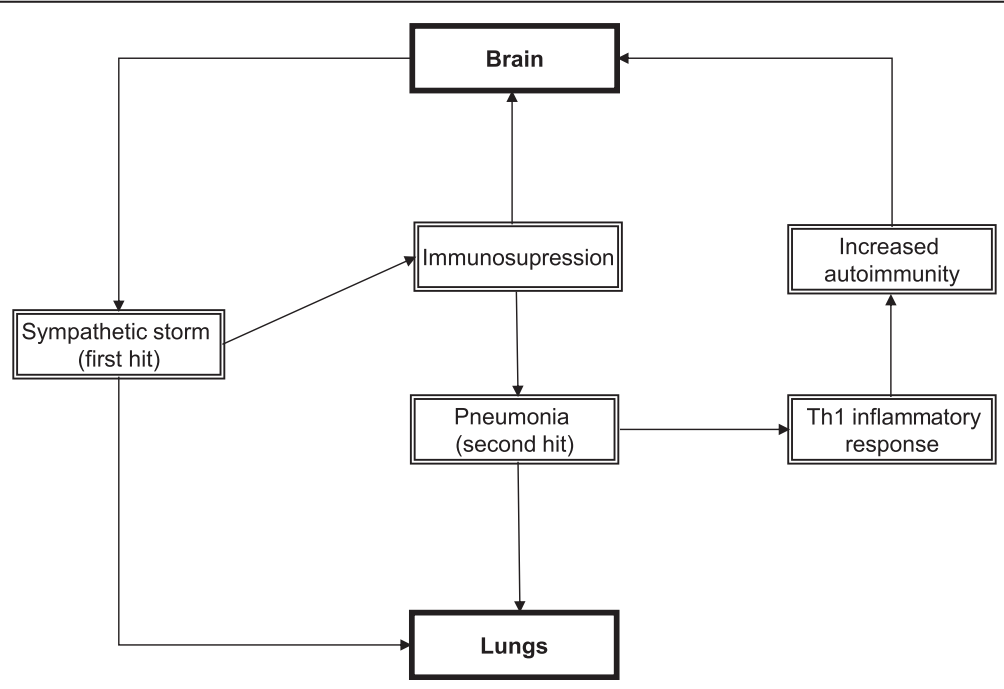

Figure 2 Vicious circle of brain-lung inflammation during ischemic stroke. 
like neurons, astrocytes and oligodendrocytes. Furthermore, the increase of antigens expression such as myelin basic protein (MBP), neuron specific enolase, S-100 or glial fibrillary acidic protein (GFAP) are observed. These components become 'visible' to the peripheral immune system, and indeed antigen presentation within days of stroke onset has been reported in cervical lymph nodes [84].

In experimental studies of severe stroke, not associated with infection, Th1 responses to MBP are uncommon. Nevertheless, the tendency to develop a Th1 response to MBP could be increased by lipopolysaccharide (LPS)mediated induction of a systemic inflammatory response at the onset of the stroke $[85,86]$. In humans, a pulmonary infection during the first 15 days after stroke increases the likelihood of developing Th1 response to MBP and GFAP [87]. A more robust immune response to MBP (and to a lesser extent to GFAP) is associated with a poor outcome at this time point [88]. Such interdependence is further supported by the findings from the Planas et al. study indicating that increased reactivity to brain-derived compounds in cervical lymph nodes and palatine tonsil is correlated with worse outcome at follow-up [84]. Pulmonary infections predominantly caused by Gram-positive organisms are associated with the Th1 response, corresponding to a fatal course of the stroke. In contrast, urinary tract infections caused primarily by Gram-negative pathogens usually do not induce Th1 response and are associated with a better prognosis [86]. It is therefore possible that pulmonary infection, despite immunosuppression, provokes an inflammatory response strong enough to upregulate the bystander adaptive autoimmune response to brain antigens in either peripheral lymphoid organs or in the brain itself [87]. However, it cannot be excluded that the better prognostic consequences of urinary infections may also be related to their lower severity and mortality and not only to differences in their potential role of favoring autoimmunity after stroke.

\section{Conclusions}

Current evidence suggests that immune-sympathetic interplay is a key point in understanding the dynamic environment of ischemic stroke. The lungs are both strongly affected and may actively participate in this interplay. We propose a model that links the 'double hit' and 'Th1 response to pneumonia' theories (Figure 2). The initial sympathetic storm directly affects the lungs (first hit), and indirectly makes them more susceptible to infection due to immunosuppression (second hit). Immunosuppresion shifts the immune response from Th1 to Th2 to protect the brain from the adaptive immune response, but pneumonia may overcome this shift, and restart Th1 bystander autoimmune response directed against CNS antigens.
In this review, we summarized the current knowledge related to the immune-sympathetic interactions with particular emphasis on the brain-lung cross-talk during this interplay. Better understanding of the pathomechanisms underlying stroke is even more urgent and important when we consider that most of the proposed experimental therapies failed to provide benefits in clinical trials in humans. In future research, data acquisition taking into account the complexity of the nervous and immune system interactions as a multisystem network most likely represents the most promising approach in describing the interrelations and pathways involved in stroke.

\section{Abbreviations}

ALI: Acute lung injury; bFGF: basic fibroblast growth factor; $\beta$-ARs: $\beta$-adrenergic receptors; CNS: central nervous system; CCR: chemokine receptors; EGF: epidermal growth factor; GFAP: glial fibrillary acidic protein; HPA: hypothalamic-pituitary-adrenal; iNOS: inducible nitric oxide synthase; IP-10: IFN- $\gamma$-induced protein 10; LPS: lipopolysaccharide; MBP: myelin basic protein; MCP-1: monocyte chemotactic protein; MIP-2: macrophage inflammatory protein 2; NPE: neurogenic pulmonary edema; NK: natural killer; ROS: reactive oxygen species; SNS: sympathetic nervous system; $T_{C} T$ : cytotoxic; $\mathrm{T}_{\mathrm{H}} \mathrm{T}$ : helper; Treg: regulatory $\mathrm{T}$.

\section{Competing interests}

The authors declare that they have no competing interests.

\section{Authors' contributions}

PJW drafted and wrote the manuscript. MR and UD commented and revised the manuscript. All authors have read and approved the final version of the manuscript.

\section{Author details}

${ }^{1}$ Institute of Human Physiology, Medical University of Gdansk, Tuwima Street 15, 80-210 Gdansk, Poland. Department of Immunopathology of Infectious and Parasitic Diseases, Medical University of Warsaw, Warsaw, Poland. ${ }^{3}$ Department of Laboratory Diagnostics and Clinical Immunology of Developmental Age, Medical University of Warsaw, Warsaw, Poland.

Received: 2 September 2014 Accepted: 2 December 2014

Published online: 24 December 2014

\section{References}

1. Davenport RJ, Dennis MS, Wellwood I, Warlow CP: Complications after acute stroke. Stroke 1996, 27:415-420

2. Langhorne P, Stott DJ, Robertson L, MacDonald J, Jones L, McAlpine C, Dick F, Taylor GS, Murray G: Medical complications after stroke: a multicenter study. Stroke 2000, 31:1223-1229.

3. Emsley HC, Hopkins SJ: Acute ischaemic stroke and infection: recent and emerging concepts. Lancet Neurol 2008, 7:341-353.

4. Katzan IL, Cebul RD, Husak SH, Dawson NV, Baker DW: The effect of pneumonia on mortality among patients hospitalized for acute stroke. Neurology 2003, 60:620-625.

5. Hannawi Y, Hannawi B, Rao CP, Suarez Jl, Bershad EM: Stroke-associated pneumonia: major advances and obstacles. Cerebrovasc Dis 2013, 35:430-443.

6. Teramoto S: Novel preventive and therapeutic strategy for post-stroke pneumonia. Expert Rev Neurother 2009, 9:1187-1200.

7. Dziewas R, Ritter M, Schilling M, Konrad C, Oelenberg S, Nabavi DG, Stögbauer F, Ringelstein EB, Lüdemann P: Pneumonia in acute stroke patients fed by nasogastric tube. J Neurol Neurosurg Psychiatry 2004, 75:852-856.

8. Riquelme R, Torres A, El-Ebiary M, de la Bellacasa JP, Estruch R, Mensa J, Fernández-Solá J, Hernández C, Rodriguez-Roisin R: Community-acquired pneumonia in the elderly: a multivariate analysis of risk and prognostic factors. Am J Respir Crit Care Med 1996, 154:1450-1455. 
9. Prass K, Braun JS, Dirnagl U, Meisel C, Meisel A: Stroke propagates bacterial aspiration to pneumonia in a model of cerebral ischemia. Stroke 2006, 37:2607-2612

10. Prass K, Meisel C, Höflich C, Braun J, Halle E, Wolf T, Ruscher K, Victorov IV, Priller J, Dirnagl U, Volk HD, Meisel A, Priller J, Dirnagl U, Volk HD, Meisel A: Stroke-induced immunodeficiency promotes spontaneous bacterial infections and is mediated by sympathetic activation reversal by poststroke T helper cell type 1-like immunostimulation. J Exp Med 2003, 198:725-736.

11. Walter U, Kolbaske S, Patejdl R, Steinhagen V, Abu-Mugheisib M, Grossmann A, Zingler C, Benecke R: Insular stroke is associated with acute sympathetic hyperactivation and immunodepression. Eur J Neurol 2013, 20:153-159.

12. ladecola C, Anrather J: The immunology of stroke: from mechanisms to translation. Nat Med 2011, 17:796-808.

13. Macrez R, Ali C, Toutirais O, Le Mauff B, Defer G, Dirnagl U, Vivien D: Stroke and the immune system: from pathophysiology to new therapeutic strategies. Lancet Neurol 2011, 10:471-480.

14. Chamorro A, Urra X, Planas AM: Infection after acute ischemic stroke: a manifestation of brain-induced immunodepression. Stroke 2007 38:1097-1103.

15. Bellinger DL, Millar BA, Perez S, Carter J, Wood C, ThyagaRajan S, Molinaro C, Lubahn C, Lorton D: Sympathetic modulation of immunity: relevance to disease. Cell Immunol 2008, 252:27-56.

16. Dziedzic T, Slowik A, Pera J, Szczudlik A: Beta-blockers reduce the risk of early death in ischemic stroke. J Neurol Sci 2007, 252:53-56.

17. Offner $H$, Subramanian S, Parker SM, Afentoulis ME, Vandenbark AA, Hurn PD: Experimental stroke induces massive, rapid activation of the peripheral immune system. J Cereb Blood Flow Metab 2006, 26:654-665.

18. Chang L, Chen Y, Li J, Liu Z, Wang Z, Chen J, Cao W, Xu Y: Cocaine-and amphetamine-regulated transcript modulates peripheral immunity and protects against brain injury in experimental stroke. Brain Behav Immun 2011, 25:260-269.

19. Woiciechowsky C, Schöning B, Daberkow N, Asche K, Stoltenburg G, Lanksch WR, Volk HD: Brain-IL-1 beta induces local inflammation but systemic anti-inflammatory response through stimulation of both hypothalamic-pituitary-adrenal axis and sympathetic nervous system. Brain Res 1999, 816:563-571.

20. Hardy J, Bednarski RM, Biller DS: Effect of phenylephrine on hemodynamics and splenic dimensions in horses. Am J Vet Res 1994, 55:1570-1578.

21. Ajmo CT Jr, Collier LA, Leonardo CC, Hall AA, Green SM, Womble TA, Cuevas J, Willing AE, Pennypacker KR: Blockade of adrenoreceptors inhibits the splenic response to stroke. Exp Neurol 2009, 218:47-55.

22. Offner $H$, Subramanian S, Parker SM, Wang C, Afentoulis ME, Lewis A, Vandenbark AA, Hurn PD: Splenic atrophy in experimental stroke is accompanied by increased regulatory $T$ cells and circulating macrophages. J Immunol 2006, 176:6523-6531.

23. Bakovic D, Pivac N, Eterovic D, Breskovic T, Zubin P, Obad A, Dujic Z: The effects of low-dose epinephrine infusion on spleen size, central and hepatic circulation and circulating platelets. Clin Physiol Funct Imaging 2013, 33:30-37.

24. Wong $\mathrm{CH}$, Jenne $\mathrm{CN}$, Lee $\mathrm{WY}$, Léger $\mathrm{C}$, Kubes $\mathrm{P}$ : Functional innervation of hepatic iNKT cells is immunosuppressive following stroke. Science 2011, 334:101-105.

25. Meisel C, Meisel A: Suppressing immunosuppression after stroke. N Engl J Med 2011, 365:2134-2136.

26. Maddahi A, Edvinsson L: Cerebral ischemia induces microvascular pro-inflammatory cytokine expression via the MEK/ERK pathway. J Neuroinflammation 2010, 7:14.

27. Maddahi A, Kruse LS, Chen QW, Edvinsson L: The role of tumor necrosis factor- $\alpha$ and TNF- $a$ receptors in cerebral arteries following cerebral ischemia in rat. J Neuroinflammation 2011, 8:107

28. Ahnstedt H, Stenman E, Cao L, Henriksson M, Edvinsson L: Cytokines and growth factors modify the upregulation of contractile endothelin ET(A) and $\mathrm{ET}(\mathrm{B})$ receptors in rat cerebral arteries after organ culture. Acta Physiol (Oxf) 2012, 205:266-278.

29. Faraco G, Moraga A, Moore J, Anrather J, Pickel VM, ladecola C: Circulating endothelin-1 alters critical mechanisms regulating cerebral microcirculation. Hypertension 2013, 62:759-766

30. Winklewski PJ, Frydrychowski AF: Cerebral blood flow, sympathetic nerve activity and stroke risk in obstructive sleep apnoea. Is there a direct link? Blood Press 2013, 22:27-33.
31. Ainslie PN, Brassard P: Why is the neural control of cerebral autoregulation so controversial? F1000Prime Rep 2014, 6:14.

32. Ter Laan M, van Dijk JM, Elting JW, Staal MJ, Absalom AR: Sympathetic regulation of cerebral blood flow in humans: a review. Br J Anaesth 2013, 111:361-367.

33. Cassaglia PA, Griffiths RI, Walker AM: Sympathetic nerve activity in the superior cervical ganglia increases in response to imposed increases in arterial pressure. Am J Physiol Regul Integr Comp Physiol 2008, 294:R1255-R1261.

34. Hamner JW, Tan CO, Lee K, Cohen MA, Taylor JA: Sympathetic control of the cerebral vasculature in humans. Stroke 2010, 41:102-109.

35. Immink RV, van Montfrans GA, Stam J, Karemaker JM, Diamant M, van Lieshout JJ: Dynamic cerebral autoregulation in acute lacunar and middle cerebral artery territory ischemic stroke. Stroke 2005, 36:2595-2600.

36. Gur AY, Gücüyener D, Uzüner N, Gilutz Y, Ozdemir G, Korczyn AD, Bornstein NM: Cerebral vasomotor reactivity of patients with acute ischemic stroke: cortical versus subcortical infarcts: an Israeli-Turkish collaborative study. J Neurol Sci 2007, 257:121-125.

37. Kamel $\mathrm{H}$, ladecola $\mathrm{C}$ : Brain-immune interactions and ischemic stroke: clinical implications. Arch Neurol 2012, 69:576-581.

38. Armstead WM, Bohman LE, Riley J, Yarovoi S, Higazi AA, Cines DB: tPA-S (481) A prevents impairment of cerebrovascular autoregulation by endogenous TPA after traumatic brain injury by upregulating p38 MAPK and inhibiting ET-1. J Neurotrauma 2013, 30:1898-1907.

39. Ishikawa M, Cooper D, Russell J, Salter JW, Zhang JH, Nanda A, Granger DN: Molecular determinants of the prothrombogenic and inflammatory phenotype assumed by the postischemic cerebral microcirculation. Stroke 2003, 34:1777-1782.

40. Nieswandt B, Kleinschnitz C, Stoll G: Ischaemic stroke: a thrombo-inflammatory disease? J Physiol 2011, 589:4115-4123.

41. Stoll G, Kleinschnitz C, Nieswandt B: Combating innate inflammation: a new paradigm for acute treatment of stroke? Ann N Y Acad Sci 2010, 1207:149-154.

42. Aloisi F: Immune function of microglia. Glia 2001, 36:165-179.

43. Nakajima K, Kohsaka S: Microglia: activation and their significance in the central nervous system. J Biochem 2001, 130:169-175.

44. Banati RB, Gehrmann J, Schubert P, Kreutzberg GW: Cytotoxicity of microglia. Glia 1993, 7:111-118.

45. Yenari MA, Xu L, Tang XN, Qiao Y, Giffard RG: Microglia potentiate damage to blood-brain barrier constituents: improvement by minocycline in vivo and in vitro. Stroke 2006, 37:1087-1093.

46. Pun PB, Lu J, Moochhala S: Involvement of ROS in BBB dysfunction. Free Radic Res 2009, 43:348-364

47. Denes A, Vidyasagar R, Feng J, Narvainen J, McColl BW, Kauppinen RA, Allan SM: Proliferating resident microglia after focal cerebral ischaemia in mice. J Cereb Blood Flow Metab 2007, 27:1941-1953.

48. Lalancette-Hébert M, Gowing G, Simard A, Weng YC, Kriz J: Selective ablation of proliferating microglial cells exacerbates ischemic injury in the brain. J Neurosci 2007, 27:2596-2605.

49. Kriz J: Inflammation in ischemic brain injury: timing is important. Crit Rev Neurobio/ 2006, 18:145-157.

50. Yilmaz G, Granger DN: Cell adhesion molecules and ischemic stroke. Neurol Res 2008, 30:783-793.

51. Gelderblom M, Leypoldt F, Steinbach K, Behrens D, Choe CU, Siler DA, Arumugam TV, Orthey E, Gerloff C, Tolosa E, Magnus T: Temporal and spatial dynamics of cerebral immune cell accumulation in stroke. Stroke 2009, 40:1849-1857.

52. Chao HJ, Hsu YC, Yuan HP, Jiang HS, Hsueh CM: The conditioned enhancement of neutrophil activity is catecholamine dependent. J Neuroimmunol 2005, 158:159-169.

53. Brait VH, Jackman KA, Walduck AK, Selemidis S, Diep H, Mast AE, Guida E, Broughton BR, Drummond GR, Sobey CG: Mechanisms contributing to cerebral infarct size after stroke: gender, reperfusion, T lymphocytes, and Nox2-derived superoxide. J Cereb Blood Flow Metab 2010, 30:1306-1317.

54. Jander S, Kraemer M, Schroeter M, Witte OW, Stoll G: Lymphocytic infiltration and expression of intercellular adhesion molecule- 1 in photochemically induced ischemia of the rat cortex. J Cereb Blood Flow Metab 1995, 15:42-51.

55. Konoeda F, Shichita T, Yoshida H, Sugiyama Y, Muto G, Hasegawa E, Morita R, Suzuki N, Yoshimura A: Therapeutic effect of IL-12/23 and their signaling pathway blockade on brain ischemia model. Biochem Biophys Res Commun 2010, 402:500-506. 
56. Shichita T, Sugiyama Y, Ooboshi H, Sugimori H, Nakagawa R, Takada I, Iwaki T, Okada Y, lida M, Cua DJ, Iwakura Y, Yoshimura A: Pivotal role of cerebral interleukin-17-producing gammadeltaT cells in the delayed phase of ischemic brain injury. Nat Med 2009, 15:946-950

57. Arumugam TV, Granger DN, Mattson MP: Stroke and T-cells. Neuromolecular Med 2005, 7:229-242.

58. Liesz A, Zhou W, Mracskó É, Karcher S, Bauer H, Schwarting S, Sun L, Bruder D, Stegemann S, Cerwenka A, Sommer C, Dalpke AH, Veltkamp R: Inhibition of lymphocyte trafficking shields the brain against deleterious neuroinflammation after stroke. Brain 2011, 134:704-720.

59. Barry M, Bleackley RC: Cytotoxic T lymphocytes: all roads lead to death. Nat Rev Immunol 2002, 2:401-409.

60. Brait VH, Arumugam TV, Drummond GR, Sobey CG: Importance of T lymphocytes in brain injury, immunodeficiency, and recovery after cerebral ischemia. J Cereb Blood Flow Metab 2012, 32:598-611.

61. Martin A, Aguirre J, Sarasa-Renedo A, Tsoukatou D, Garofalakis A, Meyer H, Mamalaki C, Ripoll J, Planas AM: Imaging changes in lymphoid organs in vivo after brain ischemia with three-dimensional fluorescence molecular tomography in transgenic mice expressing green fluorescent protein in T lymphocytes. Mol Imaging 2008, 7:157-167.

62. Gendron A, Teitelbaum J, Cossette C, Nuara S, Dumont M, Geadah D, du Souich P, Kouassi E: Temporal effects of left versus right middle cerebral artery occlusion on spleen lymphocyte subsets and mitogenic response in Wistar rats. Brain Res 2002, 955:85-97.

63. Mracsko E, Liesz A, Karcher S, Zorn M, Bari F, Veltkamp R: Differential effects of sympathetic nervous system and hypothalamic-pituitary-adrenal axis on systemic immune cells after severe experimental stroke. Brain Behav Immun 2014, 41:200-209.

64. Wang J, Yu L, Jiang C, Fu X, Liu X, Wang M, Ou C, Cui X, Zhou C, Wang J: Cerebral ischemia increases bone marrow CD4 + CD25 + FoxP3+ regulatory $T$ cells in mice via signals from sympathetic nervous system. Brain Behav Immun 2015, 43:172-83. doi:10.1016/j.bbi.2014.07.022

65. Demling R, Riessen R: Pulmonary dysfunction after cerebral injury. Crit Care Med 1990, 18:768-774.

66. Davison DL, Terek M, Chawla LS: Neurogenic pulmonary edema. Crit Care 2012, 16:212.

67. Pelosi $P$, Severgnini $P$, Chiaranda M: An integrated approach to prevent and treat respiratory failure in brain-injured patients. Curr Opin Crit Care 2005, 11:37-42.

68. Holland MC, Mackersie RC, Morabito D, Campbell AR, Kivett VA, Patel R, Erickson VR, Pittet JF: The development of acute lung injury is associated with worse neurologic outcome in patients with severe traumatic brain injury. J Trauma 2003, 55:106-111.

69. Kahn JM, Caldwell EC, Deem S, Newell DW, Heckbert SR, Rubenfeld GD: Acute lung injury in patients with subarachnoid hemorrhage: incidence, risk factors, and outcome. Crit Care Med 2006, 34:196-202.

70. López-Aguilar J, Villagrá A, Bernabé F, Murias G, Piacentini E, Real J, Fernández-Segoviano P, Romero PV, Hotchkiss JR, Blanch L: Massive brain injury enhances lung damage in an isolated lung model of ventilatorinduced lung injury. Crit Care Med 2005, 33:1077-1083.

71. Colice GL: Neurogenic pulmonary edema. Clin Chest Med 1985, 6:473-489.

72. Theodore J, Robin E: Pathogenesis of neurogenic pulmonary oedema. Lancet 1975, 2:749-751.

73. Rassler B: Contribution of $\alpha$ - and $\beta$-adrenergic mechanisms to the development of pulmonary edema. Scientifica (Cairo) 2012, 2012:829504.

74. Kalsotra A, Zhao J, Anakk S, Dash PK, Strobel HW: Brain trauma leads to enhanced lung inflammation and injury: evidence for role of P4504Fs in resolution. J Cereb Blood Flow Metab 2007, 27:963-974

75. Mascia L: Acute lung injury in patients with severe brain injury: a double hit model. Neurocrit Care 2009, 11:417-426.

76. Cobelens PM, Tiebosch IA, Dijkhuizen RM, van der Meide PH, Zwartbol R, Heijnen CJ, Kesecioglu J, van den Bergh WM: Interferon- $\beta$ attenuates lung inflammation following experimental subarachnoid hemorrhage. Crit Care 2010, 14:R157.

77. Wu S, Fang CX, Kim J, Ren J: Enhanced pulmonary inflammation following experimental intracerebral hemorrhage. Exp Neurol 2006, 200:245-249.

78. Flierl MA, Rittirsch D, Nadeau BA, Sarma JV, Day DE, Lentsch AB, Huber-Lang MS, Ward PA: Upregulation of phagocyte-derived catecholamines augments the acute inflammatory response. PLoS One 2009, 4:e4414

79. Avlonitis VS, Wigfield CH, Kirby JA, Dark JH: The hemodynamic mechanisms of lung injury and systemic inflammatory response following brain death in the transplant donor. Am J Transplant 2005, 5:684-693.

80. Sammani S, Park KS, Zaidi SR, Mathew B, Wang T, Huang Y, Zhou T, Lussier YA, Husain AN, Moreno-Vinasco L, Vigneswaran WT, Garcia JG: A sphingosine 1-phosphate 1 receptor agonist modulates brain death-induced neurogenic pulmonary injury. Am J Respir Cell Mol Biol 2011, 45:1022-1027.

81. Chiarella SE, Soberanes S, Urich D, Morales-Nebreda L, Nigdelioglu R, Green D, Young JB, Gonzalez A, Rosario C, Misharin AV, Ghio AJ, Wunderink RG, Donnelly HK, Radigan KA, Perlman H, Chandel NS, Budinger GR, Mutlu GM: $\mathrm{B}_{2}$-adrenergic agonists augment air pollution-induced IL- 6 release and thrombosis. J Clin Invest 2014, 124:2935-2946.

82. Toung TJ, Chang Y, Lin J, Bhardwaj A: Increases in lung and brain water following experimental stroke: effect of mannitol and hypertonic saline. Crit Care Med 2005, 33:203-208

83. Marrie TJ: Community-acquired pneumonia. Clin Infect Dis 1994, 18:501-513.

84. Planas AM, Gómez-Choco M, Urra X, Gorina R, Caballero M, Chamorro Á: Brain-derived antigens in lymphoid tissue of patients with acute stroke. $J$ Immunol 2012, 188:2156-2163.

85. Becker KJ, Kindrick DL, Lester MP, Shea C, Ye ZC: Sensitization to brain antigens after stroke is augmented by lipopolysaccharide. J Cereb Blood Flow Metab 2005, 25:1634-1644.

86. Zierath D, Thullbery M, Hadwin J, Gee JM, Savos A, Kalil A, Becker KJ: CNS immune responses following experimental stroke. Neurocrit Care 2010, 12:274-284

87. Becker KJ, Kalil AJ, Tanzi P, Zierath DK, Savos AV, Gee JM, Hadwin J, Carter $K T$, Shibata D, Cain KC: Autoimmune responses to the brain after stroke are associated with worse outcome. Stroke 2011, 42:2763-2769.

88. Tanzi P, Cain K, Kalil A, Zierath D, Savos A, Gee JM, Shibata D, Hadwin J, Carter K, Becker K: Post-stroke infection: a role for IL-1ra? Neurocrit Care 2011, 14:244-252.

\section{Submit your next manuscript to BioMed Central and take full advantage of:}

- Convenient online submission

- Thorough peer review

- No space constraints or color figure charges

- Immediate publication on acceptance

- Inclusion in PubMed, CAS, Scopus and Google Scholar

- Research which is freely available for redistribution 